Theoretical and Applied Informatics

ISSN $1896-5334$

Vol.24 (2012), no. 4

pp. $327-344$

DOI: $10.2478 / \mathrm{v} 10179-012-0020-5$

\title{
Examination of robust D-stability of TCP-DCR protocol
}

\author{
JERZY KLAMKA, JOLANTA TAŃCULA \\ Instytut Informatyki Teoretycznej i Stosowanej PAN w Gliwicach \\ jerzy.klamka@iitis.gliwice.pl
}

Received 1 October 2012, Revised 6 November 2012, Accepted 2 December 2012.

\begin{abstract}
This paper presents non-linear mathematical model of a computer network with a part of wireless network. The article contains an analysis of the stability of the network based on TCP-DCR, which is a modification of the traditional TCP. Block diagram of the network model was converted to a form in order to investigate the D-stability using the method of the space of uncertain parameters. Robust D-stability is calculated for constant delays values.
\end{abstract}

Keywords: Computer networks, D-stability, TCP-DCR protocol

\section{Introduction}

In the period of recent few years, the development of the Internet has had a huge impact on network technologies development. Traditional networks are replaced with wireless ones or connected with other transmission media. Fast communication and quick exchange of information require efficiently operating and efficient computer networks.

Efficiency of network applications largely depends on the queue management algorithm used in the network. AQM (Active Queue Management) in the concerned model of computer network consists in the application of RED (Random Early Detection) algorithm in feedback. RED algorithm rejects or labels packages with probability depending on the average estimate of the queue length in Internet routers.

This paper presents non-linear mathematical model of a computer network with a part of wireless network, in the form of a system of two non-linear differential equations with concentrated delay, variable in time, in state coordinates. Linearization of nonlinear equations of the model was done, and then the linearized model has been presented in the form of a flow chart. 
In further parts of the article it has been assumed that a computer network is a particular dynamic system and it can be examined using known methods of the theory of dynamic systems. Stability, apart from controllability and observability is one of basic features typical for dynamic systems. Based on the results taken from the literature [1], [2] the resistant asymptotic D-stability in the form of the presented model of a computer network was examined for one branch of a computer network.

Numeric examples of test of resistant D-stability for a real computer network have been also provided. The applied method was a method known from the literature [1], [2], related to a uncertain quasi-polynomial parameters space, which is an extension of the classic methods of D division. The method consist in determining, in the space of uncertain parameters, the set of parameter values for which the considered dynamics system is asymptotically stable. Using this method, the boundaries of the area of robust D-stability were defined.

\section{TCP-DCR protocol model}

In wireless networks, it is difficult to state whether reduction in the efficiency of TCP (Transmission Control Protocol) is caused by errors in transmission by connection overload. In order to optimize the network efficiency, various modifications of TCP standard protocol have been proposed.

One of propositions is TCP-DCR protocol (Delay Control Rate) where, the response to the receipt of duplicated acknowledgment is delayed for a limited time $\tau$. If the packet is recovered by retransmission in the lowest layer of the TCP/IP model before the end of delay, TCP-DCR, acts as if loss of packet did not happen. If, on the other hand, the packet is not recovered by retransmission before time $\tau$, TCP-DCR protocol activates algorithms against overloads by prompt retransmission and recovery of packets.

If we combine the wired base station with the wireless network [8], the model of operation of such a network based on TCP -DCR protocol can be described with nonlinear differential equations [7]:

$$
\begin{aligned}
W^{\prime}(t) & =\frac{1-P_{D}}{R(t)}+\frac{P_{D} \alpha}{R(t)+r t t}-\frac{W(t)}{2} \cdot \frac{W(t-R(t)-\tau)}{R(t-R(t)-\tau)}\left[p(t-R(t)-\tau)+P_{D}(1-\alpha)\right] \\
q^{\prime}(t) & =\left\{\begin{array}{l}
-C+\frac{N(t)}{R(t)\left(1-P_{D}\right)+(R(t)+r t t) P_{D}} W(t) \\
\max \left\{0 ;-C+\frac{N(t)}{R(t)\left(1-P_{D}\right)+(R(t)+r t t) P_{D} \alpha} W(t)\right.
\end{array}\right\}
\end{aligned}
$$

where:

- $P_{D}$ - congestion-independent loss probability in wireless part of the network, 
- $r t t$ - time, after which the wireless protocol is able to recover from an error with probability $\alpha$,

- $\tau$ - additional time to demonstrate confirmation of transmission error due to imperfect of transmission media over wireless networks,

- $W$ - congestion window size (in packets), indicating how many packets may be sent without waiting for acknowledgment of the receipt. It assumed that the traffic intensity is proportional to $\mathrm{W}$,

- $q$-queue length (in packets),

- $R(t)$ - time $r t t=\frac{q}{C}+T_{p}(\mathrm{~s})$,

- $p$ - probability of packet mark,

- $T_{P}$ - propagation delay (s),

- $N$ - number of TCP sessions.

\section{Linearization of the model and its block diagram}

We use approximation of the system dynamics by linearization of the non-linear model around the determined operating point. Taking the window size $W$ and the queue length $q$ as constant and packet marking probability $p$ as the data, the assumed operating point $\left(W_{0}, q_{0}, p_{0}\right)$ is defined by $W^{\prime}(t)=0$ and $q^{\prime}(t)=0$. Assuming for the sake of simplicity $(t-R(t))=\left(t-R_{0}\right)$ on the basis of equations (1) (2), operating point is determined, by equations

$$
\begin{gathered}
\frac{1-P_{D}}{R_{0}}+\frac{P_{D} \alpha}{R_{0}+r t t}-\frac{W_{0}^{2}(t)}{2 R_{0}} \cdot\left[p_{0}+P_{D}(1-\alpha)\right]=0 \\
-C+\frac{N W_{0}(t)}{R_{0}\left(1-P_{D}\right)+\left(R_{0}+r t t\right) P_{D}}=0
\end{gathered}
$$

After linearization of equations (1), (2) around the operating point (3) (4), we achieve a linear model of the system given in the form of the following equations [7]

$$
\begin{gathered}
W^{\prime}(t)=f_{1}(W(t), W(t-R(t)-\tau, q(t), q(t-R(t)-\tau), p(t-R(t)-\tau))= \\
f_{1}\left(W, W_{R+\tau}, q, q_{R+\tau}, p_{R+\tau}\right) \\
q^{\prime}(t)=f_{2}(q(t), W(t))=f_{2}(q, W) \\
\partial W^{\prime}=\frac{\partial f_{1}}{\partial W} \delta W+\frac{\partial f_{1}}{\partial W_{R+\tau}} \delta W_{R+\tau}+\frac{\partial f_{1}}{\partial p_{R+\tau}} \delta p_{R+\tau}+\frac{\partial f_{1}}{\partial q} \delta q+\frac{\partial f_{1}}{\partial q_{R+\tau}} \delta q_{R+\tau} \\
\delta q^{\prime}=\frac{\partial f_{2}}{\partial W} \delta W-\frac{\partial f_{2}}{\partial q} \delta q
\end{gathered}
$$


where

$$
\begin{gathered}
\frac{\partial f_{1}}{\partial W}=-\frac{W_{0}}{2} \frac{p_{0}+P_{D}}{R_{0}+r t t} \\
\frac{\partial f_{1}}{\partial W_{R+\tau}}=\frac{\partial f_{1}}{\partial W} \\
\frac{\partial f_{1}}{\partial p_{R+\tau}}=-\frac{W_{0}^{2}}{2} \frac{1}{R_{0}+r t t} \\
\frac{\partial f_{1}}{\partial q}=-\frac{\left(1-P_{D} \alpha\right) / C}{R_{0}^{2}}-\frac{P_{D} \alpha / C}{\left(R_{0}+r t t\right)^{2}} \\
\frac{\partial f_{1}}{\partial q_{R+\tau}}=\frac{W_{0}^{2}\left(p_{0}+P_{D}\right) / C}{2\left(R_{0}+r t t\right)^{2}} \\
\frac{\partial f_{2}}{\partial W}=\frac{N}{R_{0}} \\
\frac{\partial f_{2}}{\partial q}=\frac{N W_{0}}{C R_{0}^{2}}
\end{gathered}
$$

On the basis of equations (5) and (6) the network model is obtained, presented on the block diagram [7]:

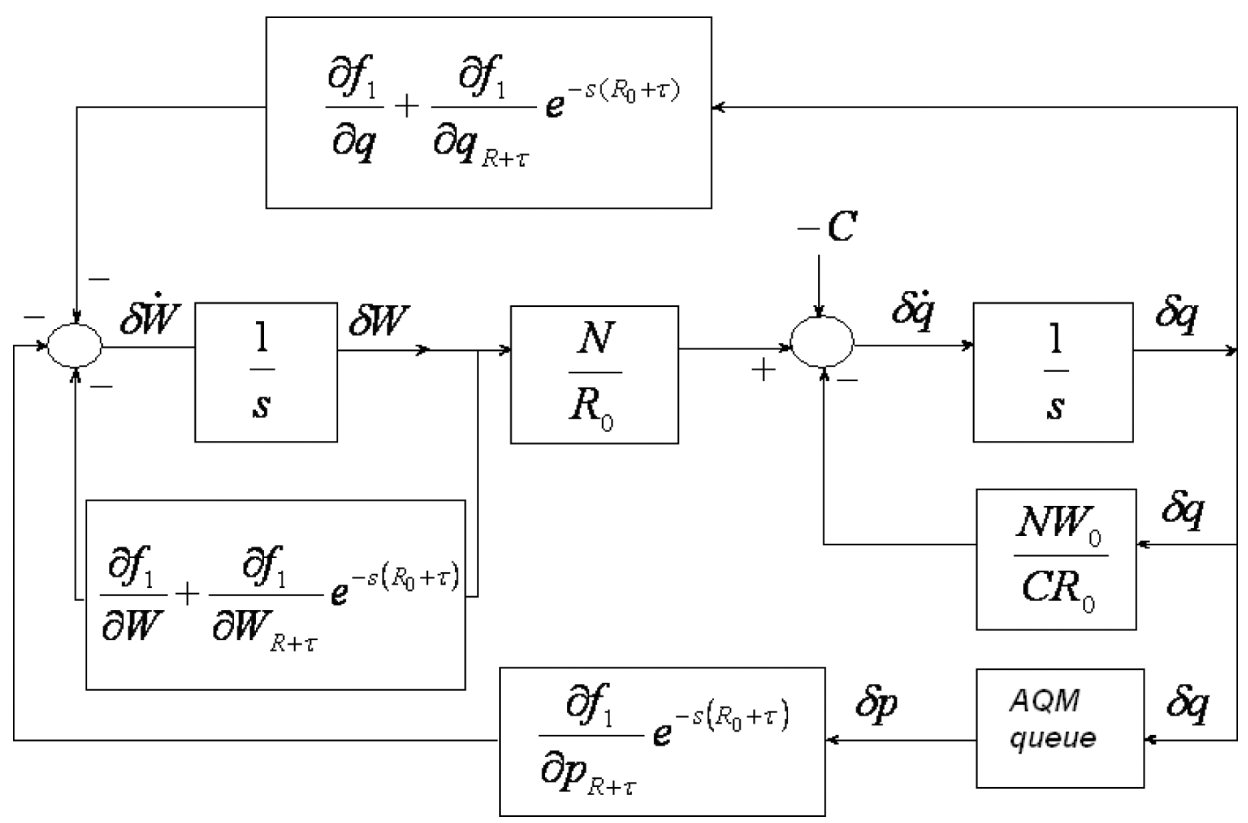

Fig. 1. Block diagram of linearized equations of the TCP-DCR model

In Figure 2 we perform to isolate $\Delta s$ as the high frequancy (parasitic). Substituting differential values to this scheme and simplifying the scheme, we obtain 


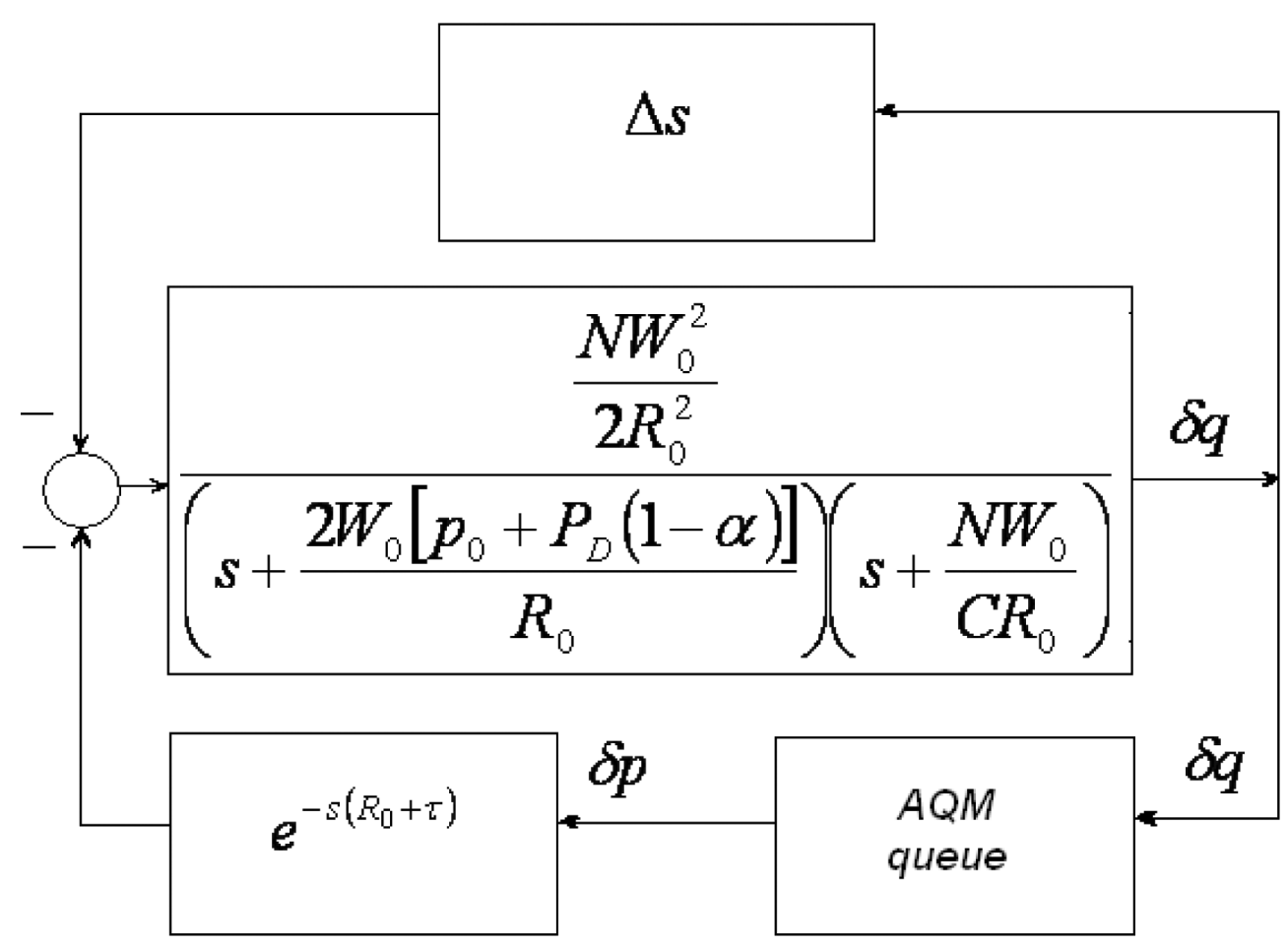

Fig. 2. Simplified block diagram

\section{Determination of transfer function of the model}

Transfer function of the open system, $P(s)=\frac{\delta q(s)}{\delta p(s)}$ in accordance with the block diagram from Fig. 2 is determined by the formula

$$
P(s)=\frac{\frac{N W_{0}^{2}}{2 R_{0}^{2}}}{\left(s+\frac{2 W_{0}\left[p_{0}+P_{D}(1-\alpha)\right]}{R_{0}}\right)\left(s+\frac{N W_{0}}{C R_{0}}\right)} \cdot e^{-s\left(R_{0}+\tau\right)}
$$

The above transfer function represents an inertial element of the second grade with permanent delay and will be used when defining the characteristic quasi-polynomial of a mathematical model. Transmittance $P(s)$ will be used in the analysis of D-stability. Fig. 2 also shows AQM block (Active Queue Management), which represents the traffic control in the network based on RED algorithm (Random Early Detection) [8].

\section{Definition and conditions of stability}

The notion and the test of stability apply to dynamic systems. Considering the computer network as a particular dynamic system, the stability test is conducted. 
Let us state a linear dynamic system with one constant delay in the form

$$
\sum_{k=0}^{n} a_{k} x^{(k)}(t-h)=0
$$

where $x^{(k)}(t)=\left(d^{k} / d t^{k}\right) x(t), a_{k}$ are real coefficients and $h>0$ is constant delay.

Since in the system there is a delay, therefore, the system stability depends on location of the elements of the characteristic quasi-polynomial.

If we assume that the characteristic quasi-polynomial has the form:

$$
\begin{gathered}
G(s, h)=\sum_{k=0}^{n} s^{k} g_{k}\left(e^{-s h}\right) \\
\text { where } \\
g_{n}\left(e^{-s h}\right) \quad \text { for } \mathrm{k}=\mathrm{n}
\end{gathered}
$$

means the dominant unit, we assume the following labelling of the dominant unit

$$
\Delta e^{-s h}
$$

The quasi-polynomial may be a quasi-polynomial of a delayed, preceded or neutral type. This type is defined on the basis of knowledge of the dominant unit. The quasipolynomial of delayed or neutral type may be both stable and unstable. On the other hand, the dominant unit of the quasi-polynomial of the delayed type is always asymptotically stable. The general definition of asymptotic stability of the quasi-polynomial can be formulated as follows [1]:

Definition 1. Quasi-polynomial of delayed or neutral type is called asymptotically stable, if there is a positive number $\varepsilon$, for which the following condition is met

$$
w(s, h) \neq 0, \quad \text { Res } \geq-\varepsilon
$$

Introducing the notion of D-stability, we need to specify the notion of $\mathrm{D}$ area.

Let $\mathrm{D}$ be a simply-connected open area on a variable complex plane or the sum of a finite number of such separable areas, i.e.

$$
D=\bigcup_{i=1}^{N} D_{i}, \quad D_{i} \bigcap D_{k}=\text { for } i \neq k
$$

We assume that $\mathrm{D}$ area is symmetrical in relation to the real axis.

Definition 2. Polynomial $w(s)$ is called D- stable if all its zeros are located in D area. 
The notion of D-stability is more general than the notion of asymptotic stability of continuous systems where D is the shifted open left half-plane i.e.

$$
D=\{s: R e s<-\gamma\}
$$

and $\gamma$ is the set real positive number.

Parametric description of edge of $\mathrm{D}$ area has the form: $f(\omega)=-\gamma+j \omega$, where $\omega \in \Omega=R$ therefore, we can be limited to the range $\Omega=[0, \infty)$ in the case of quasipolynomials with real coefficients [1].

Definition 3. The family of quasi-polynomials of delayed or neutral type is robust D-stable, if each quasi-polynomial belonging to this family is D-stable, i.e. all its zeros are located in D area.

\section{Transfer function of the system for the set model}

In order to determine the quasi-polynomial of the dynamic system in Fig. 2 we assume the following symbols for uncertain parameters:

$$
\begin{gathered}
d_{1}=\frac{N W_{0}^{2}}{2 R_{0}^{2}} \\
d_{2}=\frac{N W_{0}+2 W_{0} C\left[p_{0}+P_{D}(1-\alpha)\right]}{C R_{0}} \\
d_{3}=\frac{2 N W_{0}^{2}\left[p_{0}+P_{D}(1-\alpha)\right]}{C R_{0}^{2}}
\end{gathered}
$$

These values contain index" 0 "and mean the steady state. Thus, parameters depend on the number of TCP sessions $N$, the capacity of connection $C$, as well as the probability of loss of packets $P_{D}$ and the probability of occurrence of error $\alpha$. Dependencies that we have obtained will make it possible to analyse the stability of the computer network.

To transfer function $P(s)$ we substitute uncertain parameters $d_{1}, d_{2}, d_{3}$, which will serve us to calculate the deviation of these parameters and delay $h=R_{0}+\tau$ as a result, we obtain

$$
P(s)=\frac{d_{1}}{s^{2}+d_{2} s+d_{3}} \cdot e^{-s\left(R_{0}+\tau\right)}
$$

The main algorithm for Internet routers is RED algorithm [8]. After determining the formula of its transfer function $\mathrm{C}(\mathrm{s})[4,5]$ :

$$
C(s)=\frac{K L}{s+K}
$$


and based on the block diagram from Fig. 2, we create transfer function of the whole system described with the equation:

$$
G(s)=\frac{K L\left(s^{2}+d_{2} s+d_{3}\right)}{(s+K)\left(s^{2}+d_{2} s+d_{3}\right)+K L d_{1} e^{-s\left(R_{0}+\tau\right)}}
$$

\section{Quasi-polynomial of the system}

The quasi-polynomial of the system (12) has the form:

$$
\begin{gathered}
w\left(s, R_{0}+\tau, d\right)=w_{0}(s, d)+w_{1}(s, d) e^{-s\left(R_{0}+\tau\right)} \\
w\left(s, R_{0}+\tau, d\right)=(s+K)\left(s^{2}+d_{2} s+d_{3}\right)+K L d_{1} e^{-s\left(R_{0}+\tau\right)}
\end{gathered}
$$

where:

$$
\begin{gathered}
w_{0}(s, d)=\left(s^{3}+K s^{2}\right)+\left(s^{2}+K s\right) d_{2}+(s+K) d_{3} \\
w_{1}(s, d)=K L d_{1}
\end{gathered}
$$

that is

$$
w\left(s, R_{0}+\tau, d\right)=s^{3}+\left(K+d_{2}\right) s^{2}+\left(K d_{2}+d_{3}\right) s+\left(K d_{3}+K L d_{1}\right) e^{-s\left(R_{0}+\tau\right)}
$$

The characteristic quasi-polynomial will be used to test the stability of the fixed parameters and test method D-stability of the uncertain parameters.

\section{Stability for agreed values of delay}

Dynamic systems with a delay have an infinite the number of roots and to test their stability for agreed values of delays, graphic (frequency) are used, e.g. Mikhailov criterion based on the following theorems.

Theorem 1 [1]

The dominant unit is asymptotically stable only when graph $\Delta e^{-s\left(R_{0}+r\right)}$, prepared in the function of parameter $\omega \in[0, \infty)$, does not go around the beginning of the variable complex plane or does it go through it.

Necessary and sufficient condition

\section{Theorem 2}

The quasi-polynomial of delayed or neutral type is asymptotically stable only when on the variable complex plane, the graph of function

$$
\tilde{\varphi}\left(j \omega, R_{0}+\tau\right)=\varphi\left(j \omega, R_{0}+\tau\right) / \varphi_{o d}(j \omega)
$$


prepared for $\omega \in[0, \infty)$ does not go through the beginning of the coordinate system of the variable complex plane, and $\varphi_{o d}(j \omega)$ means the reference polynomial of degree $n$ and is

$$
\varphi_{\text {od }}(s)=(s+a)^{n},
$$

where $a$ is any real positive number.

\section{Test of stability for the set delay}

Stability will be tested with frequency method for the set delay, that is, $\left(R_{0}+\tau\right)=$ 0.22 in the space of parameters $\left(d_{1}, d_{2}, d_{3}\right)$.

Assuming $N=60, C=1000, p_{0}=0.05, W_{0}=10, R_{0}=0.2, \alpha=0.1, P_{D}=0.25$ and substituting to equations (8), (9), (10), we obtained appropriate values of parameters: $d_{1}=75000, d_{2}=30.5$ and $d_{3}=82.5$.

Based on the form of the quasi-polynomial, the dominant unit is determined and then using th. 1 and th.2, its stability is confirmed. For the above parameters, it is

$$
\Delta\left(e^{-s\left(R_{0}+\tau\right)}\right)=1
$$

A necessary condition of stability is asymptotic stability of the dominant unit. Since it has a constant value and in the complex characteristics, in respect of parameter $\omega$ it is a point, lying at the beginning of the coordinate system, it is of delayed type, which means that it is asymptotically stable.

In order to test the necessary and sufficient condition of stability of the quasipolynomial of delayed type, it is required to select an appropriate reference polynomial

$$
. w_{o d}(s)=(s+a)^{3}
$$

For the aforementioned quasi-polynomial, when $\mathrm{a}=1$, it has the form

$$
w_{\text {od }}(s)=(s+1)^{3}
$$

Substituting to quasi-polynomial

$$
w\left(s, R_{0}+\tau, d\right)=(s+K)\left(s^{2}+d_{2} s+d_{3}\right)+K L d_{1} e^{-s\left(R_{0}+\tau\right)}
$$

and dividing by the reference polynomial, we obtain the function in the form:

$\tilde{w}\left(j \omega, R_{0}+\tau, q\right)=\frac{-j \omega^{3}-\left(K+d_{3}\right) \omega^{2}+\left(K q_{2}+d_{3}\right) j \omega+K d_{3}+K L d_{1} e^{-0.22 j \omega}}{(j \omega+1)^{3}}$

We set characteristics $\tilde{w}\left(j \omega, R_{0}+\tau\right)$ for $\omega \in[0 ; \infty)$ and $\left(R_{0}+\tau\right)=0.22$.

The prepared function graph does not cross, nor does it include the beginning of the coordinate system, which means that for the set delay $\left(R_{0}+\tau\right)=0.22$ the system is stable. 


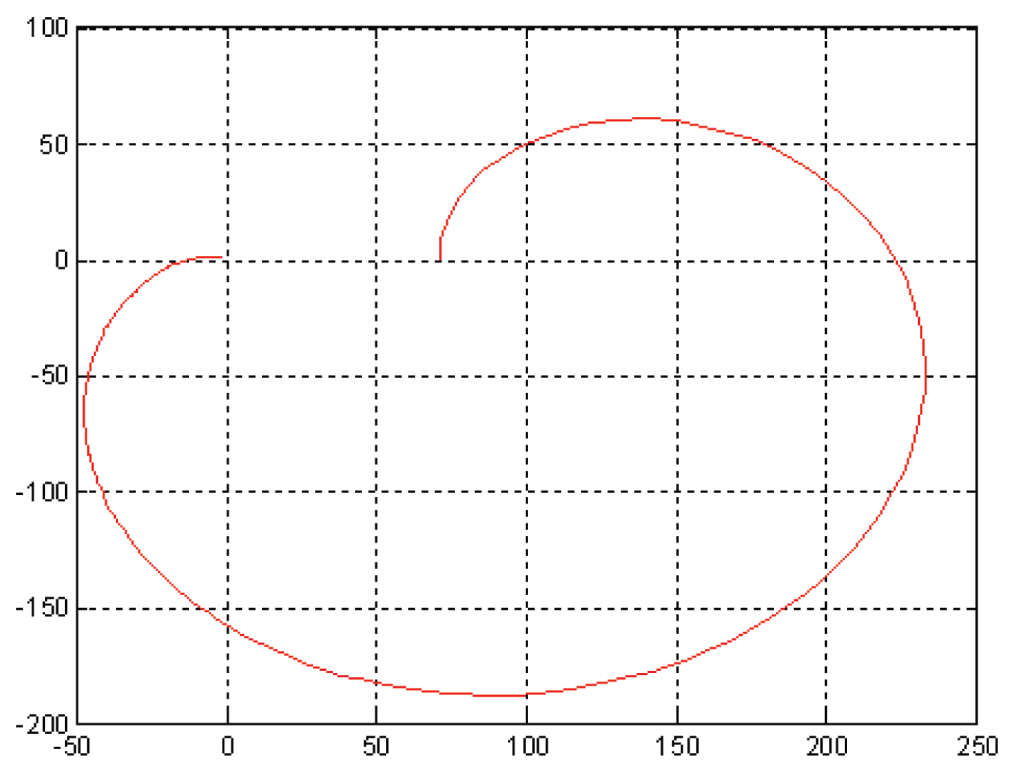

Fig. 3. Graph of function $\tilde{w}\left(j \omega, R_{0}+\tau, q\right)$ for $\left(R_{0}+\tau\right)=0.22$

\section{Test of robust D-stability with the method of uncertain parameters space}

To test robust D-stability, the method of exclusion of zero or the method of uncertain parameters space is used. Robust D-stability will be tested in the space of parameters $\left(d_{1}, d_{2}, d_{3}\right)$ in $\mathrm{D}$ area. The cuboid formed from deviations of values of parameters specified with the formula

$$
Q=\left\{d=\left[d_{1} ; d_{2} ; d_{3}\right]: d_{k} \in\left[d_{k}^{-} ; d_{k}^{+}\right] k=1,2,3\right\}, \quad Q \subset R^{3}
$$

and has been presented in Fig. 4.

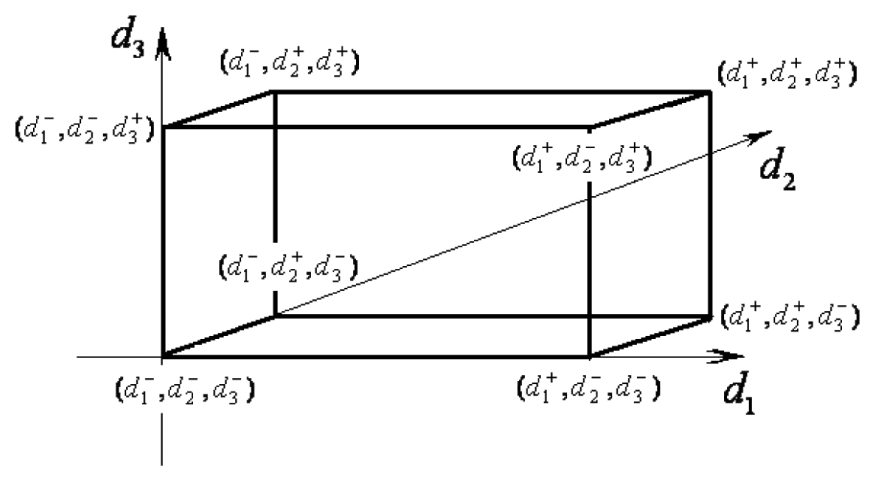

Fig. 4. Cuboid formed from deviations of uncertain parameters 
After projection on the plane, it marks out a rectangle made of deviations of parameters from their nominal values

$$
Q_{p}=\left\{d_{p}=\left[d_{1} ; d_{2}\right]: d_{k} \in\left[d_{k}^{-} ; d_{k}^{+}\right] k=1,2\right\} \quad Q \subset R^{2}
$$

It should be checked whether curves created from values of parameters $d_{3}^{0}, d_{3}^{+}, d_{3}^{-}$on plane $\left(d_{1}, d_{2}\right)$ cross rectangle $Q_{p}$ or not [1].

Zeros of the quasi-polynomial on the edge of D area are real zeros $s=-\gamma$ (if vector $d_{p}$ lies on the border of real zeros) or a pair of complex coupled zeros $s=-\gamma \pm j \omega$, for $\omega>0$ (if vector $d_{p}$ lies on the edge of complex zeros).

Then, the following dependencies occur:

$Q_{g r}=\left\{d: w\left(-\gamma, R_{0}+\tau, d\right)=0\right\}$

is the boundary of real zeros, and

$Q_{g z}=d: U(\omega, d)=0$ i $V(\omega, d)=0$ dlapewnych $\omega>0$

is the boundary of complex zeros. Family of quasi-polynomials $W\left(s, R_{0}+\tau, Q\right)=$ $\left\{w\left(s, R_{0}+\tau, d\right): d \in Q\right\}$ is resistantly D-stable only when surfaces described with the equation:

$$
w\left(-\gamma, R_{0}+\tau, d\right)=0
$$

and the set of equations

$$
\left\{\begin{array}{l}
U(\omega, d)=0 \\
V(\omega, d)=0
\end{array}\right.
$$

for parameter $\omega \epsilon(0, \infty)$, do not cross set $Q_{p}$. Therefore, we obtain the set of equations where we have two variables $d_{3}$ and $\omega$ :

$$
\begin{gathered}
d_{1}(\omega)=\frac{\left(\gamma^{3}-K \gamma^{2}+K \omega^{2} \gamma+\gamma d_{3}-K d_{3}\right)}{K L} \\
d_{2}(\omega)=\frac{\left(\gamma^{2}-\omega^{2}-K \gamma\right)\left(\gamma^{3}-K \gamma^{2}+K \omega^{2}-3 \omega^{2} \gamma-\gamma d_{3}+K d_{3}\right)+K L \omega\left(-3 \gamma^{2}+\omega^{2}+2 K \gamma-d_{3}\right)}{K L \omega(K-2 \gamma)}
\end{gathered}
$$

\section{Numeric examples}

\section{Example 1}

For deviations of uncertain parameters, we will prepare graphs of curves. We assume $\mathrm{N}=60, \mathrm{C}=1000, p_{0}=0.05, W_{0}=10, R_{0}=0.2, \alpha=0.1, P_{D}=0.25$ [7] and we substitute to the formulas (8) (9) (10), which gives appropriate values of parameters:

$$
\begin{gathered}
d_{1}^{0}=75000 \quad d_{1}^{+}=123240 \quad d_{1}^{-}=45186 \\
d_{2}^{0}=30.5 \quad d_{2}^{+}=50.1 \quad d_{2}^{-}=18.4
\end{gathered}
$$




$$
d_{3}^{0}=82.5 \quad d_{3}^{+}=154.5 \quad d_{3}^{-}=44
$$

Rectangle $Q_{p}$ created from these deviations of parameters has then the following dimensions

$$
Q_{p}=\left\{d_{p}=\left[d_{1} ; d_{2}\right]: d_{1} \in[-29814 ; 48240], d_{2} \in[-12.1 ; 19.6]\right\}
$$

Graphs curves resulting from the specified values, according to the formulas (13) and (14) values $\omega=[0.2 ; 10]$ with step 0.2 look as follows.

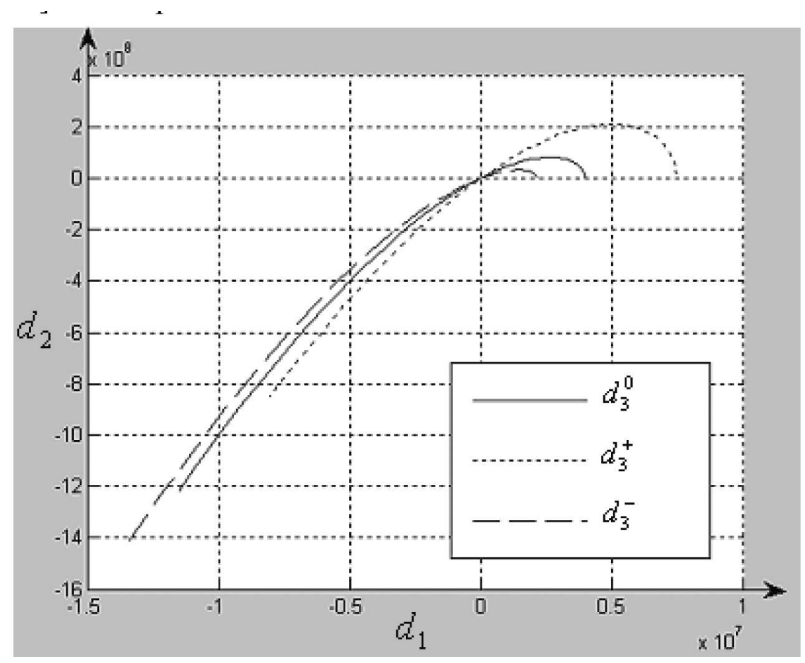

Fig. 5. Graph of curves $d_{3}^{0}, d_{3}^{+}, d_{3}^{-} 1 a \omega=[0.2: 10]$ with step 0.2

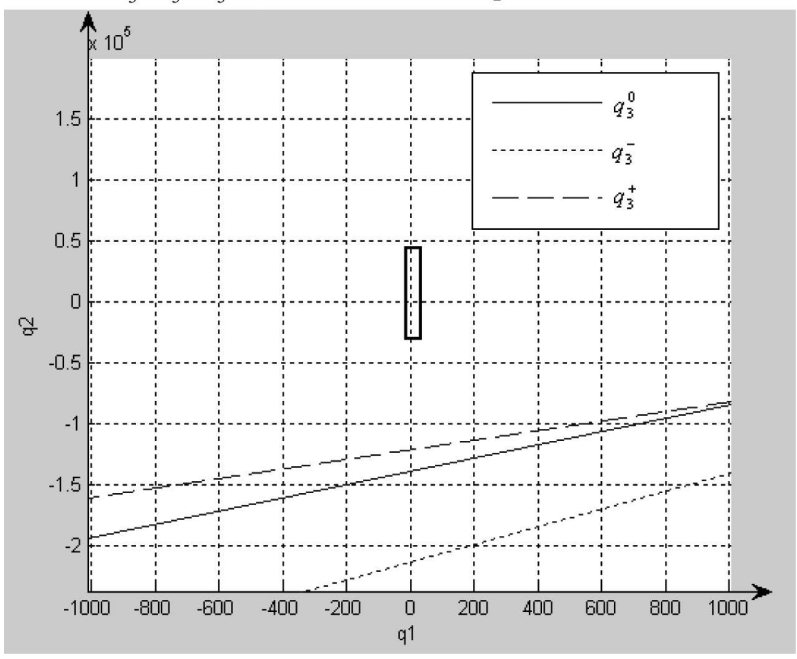

Fig. 6. Enlargement of the graph and selection the rectangle $Q_{p}$ 
From the above charts it seems that curves do not cross the rectangle $(Q)_{p}$. It means that for set $Q_{g z}$, that is the border of complex zeros, there is no unstable area.

In order to examine D-stability, we also need to mark out boundaries of real zeros, that is, to solve the equation

$$
B_{0}+\sum_{k=1}^{l} q_{k} B_{k}=0
$$

where

$$
B_{k}=w_{0}(-\gamma)+\sum_{i=1}^{m} w_{i k}(-\gamma) \exp \left(\gamma h_{i}\right), k=0,1, \ldots, 1 .
$$

On the basis of literature research [1] we assume, $s=-\gamma$ where, $\gamma=0.05 K=0.005$ and $L=1.86 \cdot 10^{-4}$. We obtain linear equation:

$$
d_{2}=-0.0004 d_{1}+20 d_{3}+0.05
$$

For value $d_{3}^{-}=-38.5$, linear equation has the form

$$
d_{2}=-0.0004 d_{1}-769.95
$$

and for $d_{3}^{+}=72$, the equation is as follows

$$
d_{2}=-0.0004 d_{1}+1440.05
$$

We obtain two straight lines on plane $\left(d_{1}, d_{2}\right)$, which are very distant from one another. It is thus required to transform the formula (15) and determine $d_{3}$. We have then

$$
d_{3}=\frac{d_{2}+0.0004 d_{1}-0.05}{20}
$$

To the formula (16) we substitute values of deviations $d_{1}=-29814$ and $d_{2}=-12.1$, and $d_{1}=48240$ and $d_{2}=19.6$ we obtain:

$$
\begin{gathered}
d_{3}^{\prime}=\frac{-12.1+0.004 \cdot(-29814)-0.05}{20}=-6.6 \\
d_{3}^{\prime \prime}=\frac{19.1+0.004 \cdot(48240)-0.05}{20}=10.6
\end{gathered}
$$

The range specified on the basis of the above calculations $[-6.6 ; 10.6]$ is within $d_{3} \in$ $[-38.5 ; 72]$. This means that straight lines for the value from this range cross the rectangle $Q_{p}$. Therefore, we should exclude values from this range from a set of solutions. As a final result the area of D-stability of the boundary of real zeros is located for value $d_{3}$ in the range $[-38.5 ;-6.6) \cup(10.6 ; 72]$. 
Since we cannot determine stability boundaries of complex zeros, because the system is always stable, then set $Q_{g z}=\emptyset$. This means that D-stability is determined by the boundary of real zeros. This, in turn, is a condition for D-stability of the whole quasipolynomial, that is, the quasi-polynomial is resistantly $\mathrm{D}$-stable within the boundaries of real zeros $[-38.5 ;-6.6) \cup(10.6 ; 72]$

\section{Example 2}

In this example, we check the changes in graphs of functions for $\mathrm{N}$ for $=80, \mathrm{C}=$ 1500, $p_{0}=0.05, W_{0}=10, R_{0}=0.2, \alpha=0.5, P_{D}=0.1 \mathrm{~L}=1.8610^{-4}, \mathrm{~K}=0.005$ and $\gamma=$ 0.05 for which values of parameters amount to, respectively:

$$
\begin{gathered}
d_{1}^{0}=100000, \quad d_{1}^{+}=164321, \quad d_{1}^{-}=60248, \\
d_{2}^{0}=12.7, \quad d_{2}^{+}=21.2, \quad d_{1}^{-}=8.1, \\
d_{3}^{0}=26.7, \quad d_{3}^{+}=56.2, \quad d_{3}^{-}=12.5
\end{gathered}
$$

Rectangle $Q_{p}$ created from these deviations of parameters has then the following dimensions

$$
Q_{p}=\left\{d_{p}=\left[d_{1} ; d_{2}\right]: d_{1} \in[-39752 ; 64321], d_{2} \in\left[\begin{array}{ll}
-4.6 ; & 8.5
\end{array}\right]\right\}
$$

Graphs of curves created from stated values and parameter $\omega=[0.2 ; 10]$ with step 0.2 are visible in Fig. 7 after magnification, we can see that rectangle is crossed by one of curves

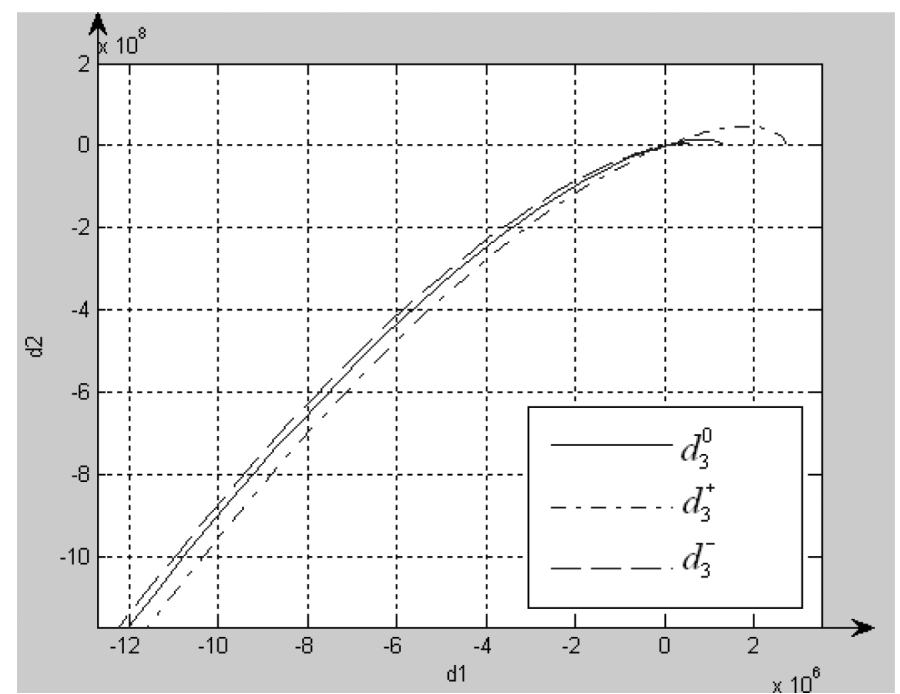

Fig. 7. Graph of curves $d_{3}^{0}=26.7, \quad d_{3}^{+}=56.2, \quad d_{3}^{-}=12.5$ for $\omega=[0.2 ; 10]$ 


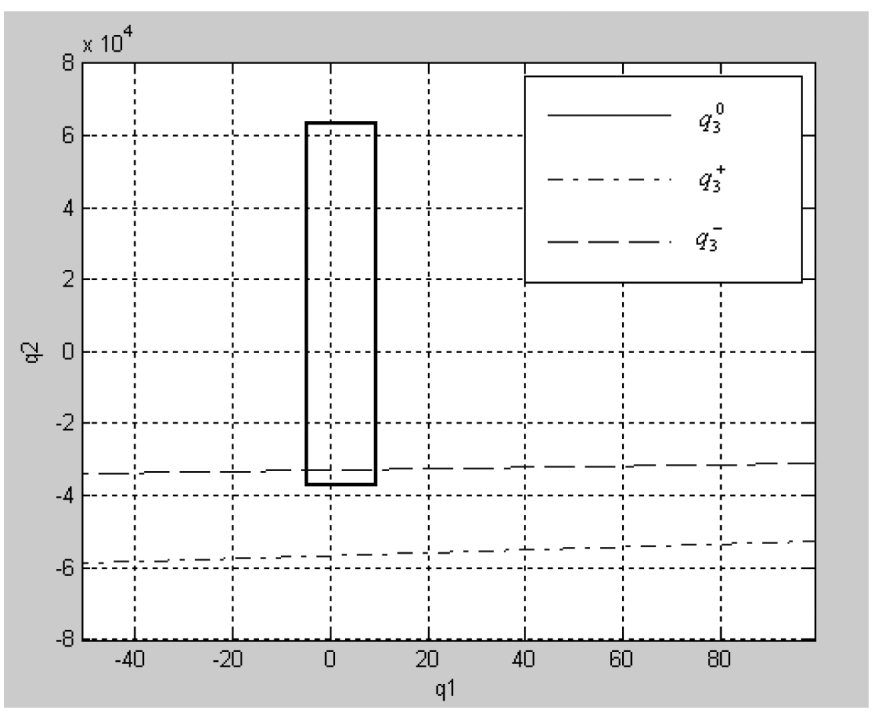

Fig. 8. Curve $d_{3}^{-}=12.5$ crosses rectangle $Q_{p}$

Fig. 8 implies that curve $d_{3}^{-}=12.5$ crosses the rectangle

$$
Q_{p}=\left\{d_{p}=\left[d_{1} ; d_{2}\right]: d_{1} \in[-39752 ; 64321], d_{2} \in[-4.6 ; 8.5]\right\},
$$

on the other hand, other curves lie far from rectangle $Q_{p}$. This means that the family of quasi-polynomials is not resistantly D-stable for $d_{3} \in[-14.2 ; 29.5]$, but for $d_{3} \in$ $[0 ; 29.5]$. The boundary of complex zeros has been determined.

Now we need to mark out boundaries of real zeros, that is, to solve the equation

$$
B_{0}+\sum_{k=1}^{l} q_{k} B_{k}=0,
$$

where

$$
B_{k}=w_{0}(-\gamma)+\sum_{i=1}^{m} w_{i k}(-\gamma) \exp \left(\gamma h_{i}\right), k=0, \ldots, 1
$$

We assume $s=-\gamma$, where $\gamma=0.05, K=0.005$, and $L=1.86 \cdot 10^{-4}$ we obtain linear equation:

$$
d_{2}=-0.0004 d_{1}+20 d_{3}+0.05
$$

For value $d_{3}^{-}=12.5$, linear equation has the form

$$
d_{2}=-0.0004 d_{1}-250
$$


and for $d_{3}^{+}=56.2$, the equation is as follows

$$
d_{2}=-0.0004 d_{1}+1124
$$

We obtain two straight lines on plane $\left(d_{1} ; d_{2}\right)$, which are very distant from one another. It is thus required to transform the formula (17) and determine $d_{3}$. We have then

$$
d_{3}=\frac{d_{2}+0.0004 d_{1}-0.05}{20}
$$

To the formula (18) we substitute values of deviations $d_{1}=-60248$ and $d_{2}=-8.1$, and $d_{1}=164321$ and $d_{2}=21.2$ we obtain:

$$
\begin{gathered}
d_{3}^{\prime}=\frac{-8.1+0.004 \cdot(-60248)-0.05}{20}=-12.5 \\
d_{3}^{\prime \prime}=\frac{21.2+0.004 \cdot 164321-0.05}{20}=33.9
\end{gathered}
$$

The range specified on the basis of the above calculations $[-12.5 ; 33.9]$ is within $d_{3} \in$ $[-14.2 ; 29.5]$. This means that straight lines for the value from this range cross rectangle $Q_{p}$. Therefore, we should exclude values from this range from a set of solutions. As a final result the area of D-stability of the boundary of real zeros is located for the value $d_{3}$ in the range $[-14.2 ;-12.5)$.

Since the boundary of stability of complex zeros and the boundary of real zeros are separable sets, this means that for the specified values $\mathrm{N}=80, \mathrm{C}=1500, \alpha=0.5, P_{D}=$ 0.1 and parameter $\omega=[0.2 ; 10]$ with step 0.2 the system is unstable.

\section{Conclusions}

In order to examine D-stability of quasi-polynomials the graphic method was applied, referred to as the method of uncertain parameters space. This method consists in setting out stability boundaries defining the operation of a computer network for the specified uncertain parameters. The method of uncertain parameter is an extension of the well-known classic method of D division.

Since checking in multi-dimensional space is not easy, therefore in the case of polynomials, we can use projecting boundaries of D-stability and set $\mathrm{Q}$ on the plane of two selected uncertain parameters.

When testing D-Stability of dynamic systems with delay, the space of limit values of parameters ensuring stability was divided into two subsets. The first subset with the boundary of complex zeros, and the second with the boundary of real zeros. For any determined values of uncertain parameters, points $\left(d_{1}(\omega), d_{2}(\omega)\right)$ have created, on the plane, a family of curves. The purpose of this article was to demonstrate how to 
select parameters $d_{3}$ and $\omega$ so that curves created in the stability boundaries determined by $d_{1}(\omega)$ and $d_{2}(\omega)$ ran as close as possible to the border rectangle $Q_{p}$ created from deviations of values of these parameters.

\section{Acknowledgements}

This research was financed by Polish Ministry of Science and Higher Education project no. N N516479640.

\section{References}

1. M. Busłowicz: Odporna stabilność układów dynamicznych liniowych stacjonarnych z późnieniami. Wydawnictwa Politechniki Białostockiej, Białystok 2002.

2. M. Busłowicz: Stabilność układów liniowych stacjonarnych o niepewnych parametrach. Dział Wydawnictw i Poligrafii, Białystok 1997.

3. A. Tanenbaum: Sieci komputerowe, Wydawnictwo Helion, Gliwice 2004.

4. C.V. Hollot, V. Misra, D. Towsley, Wei Bo Gong: A Control Theoretical Analysis of Red, Infocom 2001, Vol. 3 p. 1510-1519.

5. C.V. Hollot, V. Misra, D. Towsley, Wei Bo Gong: Analysis and Design of Controllers for AQM Routers Supporting TCP Flows, IEEE System and Control Methods for Communication Networks 2002, Vol. 47, No. 6.

6. S. Bhandarkar, N. Sadry, A.L.N. Reddy, N. Vaidya: TCP-DCR: A novel protocol tolerating wireless channel errors, IEEE Transaction on Mobile Computing 2005, Vol. 4 No. 5.

7. T. Czachórski, K. Grochla, F. Pekergin: Stability and Dynamics of TCP-NCR(DCR) protocol in presence of UDP flows, Proceedings of Third international EURO-NGI network of excellance conference on Wireless systems and mobility in next generation internet 2006, Springer-Verlag Berlin, Heidelberg p. 241-254.

8. M. Hassan, J. Raj: Wysoko wydajne sieci TCP/IP, Wydawnictwo Helion, Gliwice 2004.

\section{Analiza D-stabilności protokołu TCP-DCR}

\section{Streszczenie}

W pracy przedstawiono nieliniowy model matematyczny sieci komputerowej w postaci układu dwóch równań różniczkowych ze skupionym zmiennym w czasie opóźnieniem we współrzędnych stanu. Przedstawiono model w postaci schematu blokowego, a następnie dokonano przekształceń schematu zgodnie z linearyzacją równań. 
Wydajność aplikacji w dużym stopniu zależy od stosowanego w sieci algorytmu zarządzania kolejką. Aktywne zarządzanie kolejką (Active Queue Management) w rozpatrywanym modelu sieci komputerowej polega na zastosowaniu algorytmu RED (Random Early Detection) w sprzężeniu zwrotnym.

Jeśli przyjąć, że sieć komputerowa jest specyficznym układem dynamicznym to możemy poddać badaniu stabilności taki układ. Analityczne metody badania D-stabilności mogą być trudne do sprawdzenia, dlatego w niniejszej pracy zaproponowano metody graficzne znane z literatury. Przedstawiono również przykłady liczbowe badania stabilności dla rzeczywistej sieci komputerowej. Wykorzystano metodę częstotliwościową oraz metodę przestrzeni niepewnych parametrów quasi-wielomianów, która jest rozwinięciem klasycznej metody podziału D. Polega ona na wyznaczeniu w przestrzeni niepewnych parametrów quasi-wielomianów zbioru takich wartości niepewnych parametrów, dla których jest on asymptotycznie stabilny. Przy użyciu tej metody określono granice obszaru odpornej D-stabilności.

Wyznaczenie granic stabilności układu pozwoli zaprojektować sieć bezprzewodową bardziej wydajną, szybszą i odporną na błędy. 